\title{
Synthesis of Silica Xerogels with High Surface Area using Acetic Acid as Catalyst
}

\author{
Leliz T. Arenas, ${ }^{a}$ Carolina W. Simm, ${ }^{a}$ Yoshitaka Gushikem, ${ }^{b}$ Silvio L. P. Dias, ${ }^{a}$ Celso C. Moro, ${ }^{a}$ \\ Tania M. H. Costa ${ }^{*, a}$ and Edilson V. Benvenutti ${ }^{*, a}$ \\ ${ }^{a}$ Instituto de Química, Universidade Federal do Rio Grande do Sul, CP 15003, \\ 91501-970 Porto Alegre-RS, Brazil \\ ${ }^{b}$ Instituto de Química, Universidade Estadual de Campinas, CP 6154, 13084-971 Campinas-SP, Brazil
}

\begin{abstract}
Nesse trabalho foi estudada a influência do ácido acético na estrutura de poros e na área superficial de sílicas preparadas pelo método sol-gel. Condições experimentais de síntese, tais como temperatura de policondensação e solventes, também foram estudadas. Isotermas de adsorção de $\mathrm{N}_{2}$ das amostras foram classificadas como do tipo 1, típicas de materiais microporosos, o que explica os altos valores de área superficial obtidos. A adição simultânea dos ácidos acético e clorídrico como catalisadores e de acetona como solvente, bem como o emprego de uma temperatura de policondensação de $20^{\circ} \mathrm{C}$, possibilitaram a preparação de sílicas amorfas com valores de área superficial de até 850 $\mathrm{m}^{2} \mathrm{~g}^{-1}$. $\mathrm{O}$ alto valor de área superficial dessas amostras pode ser explicado principalmente pela microporosidade e também pelo tamanho nanométrico das partículas.
\end{abstract}

The influence of acetic acid on the pore structure and surface area of silica prepared by the sol-gel method was investigated. Experimental conditions of synthesis, such as gelation temperature and solvents, were also studied. $\mathrm{N}_{2}$ adsorption isotherms of the samples were type 1 , typical of microporous materials, explaining the high surface area values (BET) observed. The simultaneous addition of acetic and hydrochloric acids as catalysts and of acetone as solvent, together with the use of a gelation temperature of $20{ }^{\circ} \mathrm{C}$, made it possible to prepare amorphous silica materials with surface area values up to $850 \mathrm{~m}^{2} \mathrm{~g}^{-1}$. The high surface area value of these samples could be explained by the microporosity and the nanometric size of the particles.

Keywords: silica, microporous materials, high surface area, acetic acid

\section{Introduction}

Inorganic materials possessing high surface area have been largely studied due to their possible application as sorbents, catalysts, sensors, molecular sieves etc. ${ }^{1-4}$ In general, these materials are formed mainly by silicon and aluminum oxides, with ordered structures like those presented by zeolites and clays. Since the 1990s, after the appearance of a new class of highly ordered silica mesoporous materials called MCMs (Mesoporous Crystalline Materials), the interest in high surface area silicas was renewed. ${ }^{5-8}$ Several synthetic methods aiming at the preparation of materials with high surface area and tailored pore size in the micro, meso and macropore range have been proposed. Among the proposed methods, the sol-gel synthesis appears as an interesting alternative process to obtain these materials..$^{9-11}$ This method, that is

*e-mail: taniaha@iq.ufrgs.br; benvenutti@iq.ufrgs.br based on hydrolysis and polycondensation of silicon or metal alkoxides, allows the preparation of materials with different morphological characteristics by varying experimental synthetic conditions such as $\mathrm{pH}$, solvent, temperature and catalyst. ${ }^{9,12,13}$ The reaction medium can be acid, neutral or basic, depending on the inorganic catalyst added, as, for example, $\mathrm{HCl}, \mathrm{HF}$ or $\mathrm{NH}_{3} \cdot{ }^{14}$ Organic catalysts such as citric and acetic acids have been also used. ${ }^{15-17}$ Anionic and cationic surfactants, as well as water soluble polymers, have also been added to sol-gel systems in order to produce materials with controlled porosity. ${ }^{18,19}$

The use of acetic acid as catalyst has been reported for several sol-gel systems, as in the synthesis of high purity dense silica glass microspheres, ${ }^{20,21}$ photoluminescent lanthanide-doped silica microspheres with controllable size, ${ }^{22}$ silica-based hybrid materials ${ }^{17,23}$ and titania-based systems. ${ }^{24,25}$ Although the mechanism of acid acetic action is not completely known, it has already been well studied in several works as follows. 
It was first proposed by Pope and Mackenzie ${ }^{26}$ that the acetic acid solvolysis occurs by a two-step mechanism involving the formation of ester as intermediate. In the sequence, a consensus was established on the formation of intermediate metal acetate species. ${ }^{15,17,24}$ For pure silica systems, besides acting as acid catalyst, acetic acid can influence the kinetics of polycondensation, decreasing the speed of reaction and consequently influencing the primary particle growth of the gel, or causing a narrow particle diameter distribution. ${ }^{15,16}$ In a previous work by our research group, ${ }^{27}$ we had observed that in silica/cellulose sol-gel systems, the presence of acetic acid produced high surface area hybrid materials and, as far as we know, this fact has not been reported yet. Thus, we believe that acetic acid can be better explored as an important factor in the sol-gel synthesis of controlled pore size and high surface area materials.

In this work, the effects of the presence of acetic acid on the pore structure and surface area of silica xerogels were investigated. The influence of experimental conditions such as the solvent used and the gelation temperature were also studied.

\section{Experimental}

\section{Synthesis of silica xerogels}

Two sample series of silica xerogels were prepared by the sol-gel method based on hydrolysis and polycondensation of tetraethylorthosilicate (TEOS) in acid medium. Table 1 summarizes the synthetic conditions for the silica xerogel samples of the first series. They were obtained from $22 \mathrm{mmol}$ of TEOS dissolved in the solvent specified in Table 1. Afterwards, the catalyst and water, in stoichiometric ratio with $\mathrm{Si} \mathrm{r}=$ $4 / 1(1.6 \mathrm{~mL})$, were added to the precursor solutions, under stirring, except in the case of sample A, that was synthesized without water. The samples were covered and left for gelation and solvent evaporation, without sealing, for two weeks at $20 \pm 5^{\circ} \mathrm{C}$. The xerogels obtained were comminuted in an agate mortar, washed with 10 $\mathrm{mL}$ of water and ethanol and oven-dried at $100{ }^{\circ} \mathrm{C}$. Nine samples were prepared, varying the solvent and the catalyst employed, either glacial acetic acid or $\mathrm{HCl}$ solution $0.1 \mathrm{~mol} \mathrm{~L}^{-1}$, or both, according to Table 1 .

The second series was obtained using the experimental conditions of sample E (Table 1) and varying the gelation temperature. Temperatures of 5, 15, 20, 25, 30 and $50 \pm$ $1{ }^{\circ} \mathrm{C}$ were employed. The precise temperatures used in this sample series were attained with the use of a water-
Table 1. Experimental conditions for the synthesis of the first silica xerogel series

\begin{tabular}{lcccc}
\hline Sample & Solvent & $\begin{array}{c}\text { Total solvent } \\
\text { volume/mL }\end{array}$ & Catalyst & $\begin{array}{c}\text { Catalyst } \\
\text { volume/mL }\end{array}$ \\
\hline A $^{\text {a }}$ & acetone & 5 & acetic acid & 5 \\
B & acetone & 5 & acetic acid & 5 \\
C & acetone:ethanol (1:1) & 5 & acetic acid & 5 \\
D & ethanol & 5 & acetic acid & 5 \\
E & acetone & 5 & acetic acid / HCl & $5 / 0.1$ \\
F & ethanol & 5 & acetic acid / HCl & $5 / 0.1$ \\
G & acetone & 10 & $\mathrm{HCl}$ & 0.2 \\
H & ethanol & 5 & $\mathrm{HCl}$ & 0.2 \\
I & acetone:ethanol (1:1) & 10 & $\mathrm{HCl}$ & 0.2 \\
\hline
\end{tabular}

${ }^{\mathrm{a}}$ without water.

containing thermostated system or of an oil bath. The same gelation and washing procedures described for the first series were used in this case.

\section{$N_{2}$ adsorption-desorption isotherms}

The nitrogen adsorption-desorption isotherms of xerogels previously degassed at $150{ }^{\circ} \mathrm{C}$ were determined at liquid nitrogen boiling point in a homemade volumetric apparatus, connected to a vacuum line system employing a turbo molecular Edward vacuum pump. The pressure measurements were made using a capillary $\mathrm{Hg}$ barometer. The specific surface areas of hybrid materials were determined from the BET (Brunauer, Emmett and Teller) multipoint method ${ }^{28}$ and the pore size distribution was obtained using the BJH (Barret, Joyner and Halenda) method. ${ }^{29}$

\section{SAXS analyses}

Small angle X-ray scattering (SAXS) data were obtained on a Shimadzu XD3A equipment, using the $\mathrm{Cu} \mathrm{K}_{\alpha}$ radiation source. The average pore radii of the samples were obtained by using the Guinier law. ${ }^{30,31}$ This law establishes that the scattering intensities I (q) are described as $\ln I(q)=\ln I_{o}-\left(R G^{2} q^{2}\right) / 3$, where RG is the gyration radii and $\mathrm{q}$ is defined as $\mathrm{q}=(4 \pi \operatorname{sen} \theta) /$ $\lambda$, where $\theta$ is the scattering angle and $\lambda$ the wavelength of the X-ray used. The gyration radii could be calculated by the equation $R G=(3 p)^{1 / 2}$, where $p$ is the slope of the Guinier plot, (ln (q) vs. $\mathrm{q}^{2}$ ). Considering spherical pores, the pore radii were obtained by the equation $\mathrm{Rp}=$ $(5 / 3)^{1 / 2}$ RG.

\section{TEM analyses}

Transmission Electron Microscopy images were obtained on a JEOL JEM 2010 apparatus, with an 
acceleration voltage of $200 \mathrm{kV}$, using powdered samples. The magnification used was up to 500,000 times. Samples were ground to very fine powders in an agate mortar, dispersed in isopropylic alcohol and ultrasonicated for 20 minutes. The samples were then settled over a copper grid for analysis.

\section{Results and Discussion}

The results of surface area, pore volume and gelation time of the first sample series are shown in Table 2. In a general way, in the present work, samples prepared with acetic acid as the only catalyst (samples B, C and D in Table 1), present higher surface area values, near twice as high as those prepared only with hydrochloric acid (samples G, H and I, ca. $370 \mathrm{~m}^{2} \mathrm{~g}^{-1}$ ). One exception is sample A, which was synthesized with acetic acid but without initial water addition, for which the surface area obtained was $440 \mathrm{~m}^{2} \mathrm{~g}^{-1}$. The highest surface area value was obtained for sample E, when both acid catalysts were used at the same time, and acetone as solvent, being this value $825 \mathrm{~m}^{2} \mathrm{~g}^{-1}$. Additionally, it can be observed in Table 1 that, for samples $\mathrm{E}$ and $\mathrm{F}$, where hydrochloric and acetic acids were simultaneously used, the gelation time was lower than those observed for reactions catalyzed by acetic acid only.

Table 2. Surface area and pore volume of the first xerogel series

\begin{tabular}{cccc}
\hline Sample & $\begin{array}{c}\text { Surface area/ } \\
\left( \pm 25 \mathrm{~m}^{2} \mathrm{~g}^{-1}\right)\end{array}$ & $\begin{array}{c}\text { Pore volume/ } \\
\left( \pm 0.03 \mathrm{~cm}^{3} \mathrm{~g}^{-1}\right)\end{array}$ & $\begin{array}{c}\text { Gelation } \\
\text { time/day }\end{array}$ \\
\hline $\mathrm{A}$ & 440 & 0.24 & 3 \\
$\mathrm{~B}$ & 750 & 0.18 & 2 \\
$\mathrm{C}$ & 680 & 0.18 & 4 \\
$\mathrm{D}$ & 785 & 0.31 & 3 \\
$\mathrm{E}$ & 825 & 0.19 & 2 \\
$\mathrm{~F}$ & 620 & 0.11 & 2 \\
$\mathrm{G}$ & 335 & 0.10 & 1 \\
$\mathrm{H}$ & 425 & 0.12 & $<1$ \\
$\mathrm{I}$ & 355 & 0.10 & $<1$ \\
\hline
\end{tabular}

It has already been reported that the use of acetic acid in silica sol-gel systems can produce changes in the microstructure and final characteristics of the materials, allowing the control of particle size distribution. ${ }^{15,16}$ The silica sol-gel films obtained are crack-free and show optical transparency. ${ }^{16,17}$ Although the mechanisms which govern the formation of these materials are not well known, there is a general consensus about the formation of the species $\equiv \mathrm{Si}-\mathrm{OOCCH}_{3}$ and $\mathrm{CH}_{3} \mathrm{COOC}_{2} \mathrm{H}_{5}$ in TEOS/ ethanol systems. The $\equiv \mathrm{Si}-\mathrm{OOCCH}_{3}$ species were identified by infrared spectroscopy. ${ }^{15,20}$ It was proposed that, in the presence of acetic acid, several reaction steps could occur, which are shown in Scheme 1. ${ }^{15,17}$

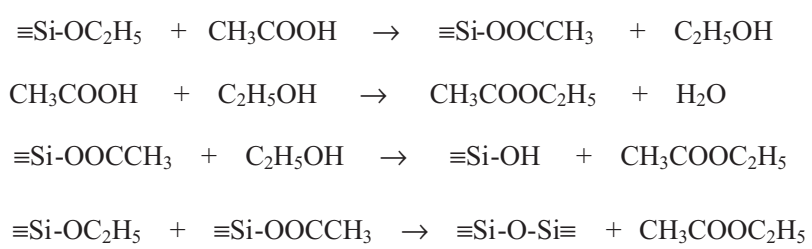

Scheme 1.

It has been observed that the addition of acetic acid to sol-gel silica systems produces a reduction in gelation rates in comparison with the addition of inorganic acids. This effect can be overcome by the addition of water; however, water also influences the microstructure of the materials. ${ }^{13,17,32}$ Based on results obtained in previous works, the water/TEOS molar ratio used was $4: 1$, since the use of this molar ratio resulted in hybrid or pure silica xerogels having high surface area. ${ }^{5,13,32}$

Figure 1 shows the $\mathrm{N}_{2}$ adsorption isotherms for the first sample series. It can be seen that all curves are type 1 isotherms, typical of microporous materials. ${ }^{33}$ This result can explain the high surface area values observed for this sample series.

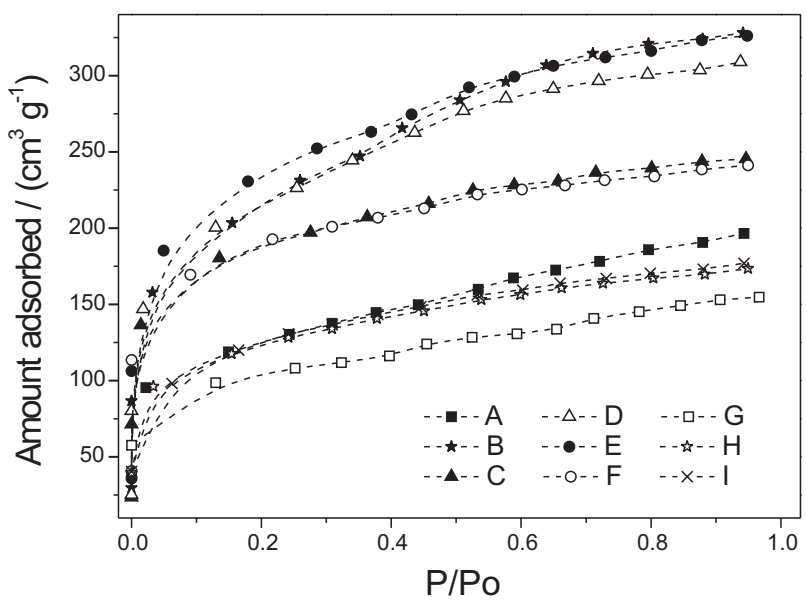

Figure 1. $\mathrm{N}_{2}$ adsorption isotherms for the first sample series.

Considering that the highest surface area value of the silica xerogels was obtained for sample E, where acetone was used as solvent and acetic and hydrochloric acids as catalysts, we decided to study this xerogel sample preparation in a more detailed way. In previous works with silica-based hybrid systems, it has been observed that the gelation temperature is an important parameter in determining surface area values. ${ }^{12,34}$ In those papers, a decrease in surface area values with increasing temperature (from room temperature to $50{ }^{\circ} \mathrm{C}$ ) was reported, being this fact accompanied by an increase in organic incorporation of the xerogels. In the present paper, a second series of 
pure silica was prepared, maintaining the experimental conditions of the sample $\mathrm{E}$ and varying the gelation temperature in a more controlled way. The used values were $5,15,20,25,30$ and $50 \pm 1{ }^{\circ} \mathrm{C}$. For this new sample series, the samples obtained were named E5, E15, E20, E25, E30 and E50, respectively. The surface area values obtained for these samples are presented in Table 3. The highest surface area value attained was of $850 \mathrm{~m}^{2} \mathrm{~g}^{-1}$ for the sample submitted to a gelation temperature of $20^{\circ} \mathrm{C}$ (sample E20). For lower temperatures, a decrease in surface area occurred and, for higher temperatures, there was also a slight decrease according to the results cited above, already reported for silica-based hybrid materials. ${ }^{12,34}$

Table 3. Surface area and pore volume of the second xerogel series

\begin{tabular}{ccccc}
\hline Sample & $\begin{array}{c}\text { Temperature/ } \\
{ }^{\circ} \mathrm{C}\end{array}$ & $\begin{array}{c}\text { Surface area/ } \\
\left( \pm 25 \mathrm{~m}^{2} \mathrm{~g}^{-1}\right)\end{array}$ & $\begin{array}{c}\text { Pore volume/ } \\
\left( \pm 0.03 \mathrm{~cm}^{3} \mathrm{~g}^{-1}\right)\end{array}$ & $\begin{array}{c}\text { Gelation } \\
\text { time/day }\end{array}$ \\
\hline E0 & 0 & 520 & 0.13 & 14 \\
E15 & 15 & 700 & 0.16 & 3 \\
E20 & 20 & 850 & 0.24 & 2 \\
E25 & 25 & 670 & 0.17 & 2 \\
E30 & 30 & 630 & 0.15 & 1 \\
E50 & 50 & 630 & 0.15 & $<1$ \\
\hline
\end{tabular}

For the sample E20, that presents the highest surface area value, we decided to improve the characterization. The pore size was determined by SAXS analysis. From the Guinier plot, it was possible to adjust the curve with a linear fitting presenting slope of -0.2598 . The radii value obtained was $1.1 \mathrm{~nm}$. Transmission electron microscopy images were also obtained (Figure 2). It is possible to see that, at the magnification employed, the silica xerogel sample E20 presents particles with diameter lower than $50 \mathrm{~nm}$.

Although the high specific surface area value for this sample is mainly due to the microporosity contribution, as observed from the $\mathrm{N}_{2}$ isotherms (Figure 1 and Tables 2 and 3), there is also a contribution of the external area of the nanometric-sized xerogel particles, observed on TEM images. Additionally, these observed nanostructures could be agglomerates presenting internal structures, and the surface area contribution of these presumably primary particles cannot be discarded.

Considering morphological aspects, the main papers published about the silica/acetic acid system report the preparation of microspheres with controlled size and shape. ${ }^{15,20-22}$ In our case, the materials presented different characteristics not observed up to now, such as very high surface area and nanometric particle size with diameter between 20 and $50 \mathrm{~nm}$. Although the water / acetic acid / TEOS ratios used were the same, 4:4:1, there are important experimental differences in the synthetic method as
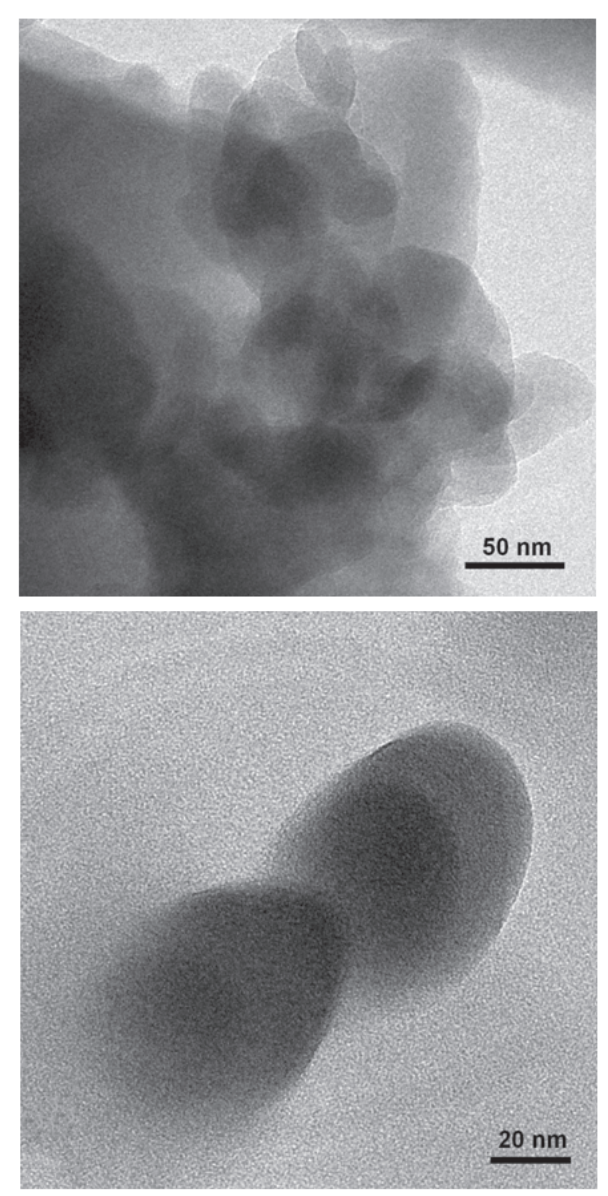

Figure 2. Transmission electron microscopy images of the sample E20.

follows: in the cited papers solvents were not used and the reaction was performed under vigorous stirring. On the other hand, in the present work ethanol and acetone were employed as solvents to promote homogeneity, considering that water and TEOS are immiscible.

\section{Conclusions}

The use of acetic acid in sol-gel silica systems was satisfactory to produce high surface area microporous materials without addition of any template. The simultaneous addition of acetic and hydrochloric acids as catalysts and acetone as solvent made possible to prepare amorphous silica materials with surface area values up to $850 \mathrm{~m}^{2} \mathrm{~g}^{-1}$, taking a gelation time of two days. The gelation temperature also influences the surface area, being the highest value attained at gelation temperature of $20^{\circ} \mathrm{C}$. For this material, the estimated micropore radius, obtained by SAXS, was $1.1 \mathrm{~nm}$, and the observed particle size was below $50 \mathrm{~nm}$. The high surface area value of this sample could be explained mainly by the microporosity and also by the nanometric size of particles. 


\section{Acknowledgments}

We thank FAPERGS (Fundação de Amparo à Pesquisa no Estado do Rio Grande do Sul), FAPESP (Fundação de Amparo à Pesquisa no Estado de São Paulo) and CNPq (Conselho Nacional de Desenvolvimento Científico e Tecnológico-Brazil), for financial support and grants. We also thank CME-Centro de Microscopia EletrônicaUFRGS for the use of the TEM equipment.

\section{References}

1. Schuth, F.; Annu. Rev. Mater. Res. 2005, 35, 209.

2. Corma, A.; Chem. Rev. 1997, 97, 2373.

3. Adebajo, M. O.; Frost, R. L.; Kloprogge, J. T.; Carmody, O.; Kokot, S.; J. Porous Mater. 2003, 10, 159.

4. Valdes, M. G.; Perez-Cordoves, A. I.; Diaz-Garcia, M. E.; Trends Anal. Chem. 2006, 25, 24.

5. Kato, M.; Shigeno, T.; Kimura, T.; Kuroda, K.; Chem. Mater. 2005, 17, 6416.

6. Xiao, F. S.; Top. Catal. 2005, 35, 9.

7. Su, B. L.; Léonard, A.; Yuan, Z. Y.; Chimie 2005, 8, 713.

8. Kresge, C. T.; Leonowicz, M. E.; Roth, W. J.; Vartuli, J. C.; Beck, J. S.; Nature 1992, 359, 710.

9. Shea, K. J.; Loy, D. A.; Chem. Mater. 2001, 13, 3306.

10. Burleigh, M. C.; Dai, S.; Hagaman, E. W.; Lin, J. S.; Chem. Mater. 2001, 13, 2537.

11. Kato, M.; Sakai-Kato, K.; Toyo'oka, T.; J. Sep. Sci. 2005, 28, 1893.

12. Gay, D. F. S.; Gushikem, Y.; Moro, C. C.; Costa, T. M. H.; Benvenutti, E. V.; J. Sol-Gel Sci. Technol. 2005, 34, 189.

13. Azolin, D. R.; Celso, C. C.; Costa, T. M. H.; Benvenutti, E. V. B.; J. Non-Cryst. Solids 2004, 337, 201.

14. Brinker, C. J.; Scherer G. W.; Sol-Gel Science, Academic Press: London, 1990.

15. Karmakar, B.; De, G.; Kundu, D.; Ganguli, D.; J. Non-Cryst. Solids 1991, 135, 29.

16. Liu, Y.; Ren, W.; Zhang, L.; Yao, X.; Thin Solid Films 1999, 353, 124.
17. Stathatos, E.; Lianos, P.; Orel, B.; Vuk, A. S.; Jese, R.; Langmuir 2003, 19, 7587.

18. Raman, N. K.; Anderson, M. T.; Brinker, C. J.; Chem. Mater. 1996, 8, 1682.

19. Xiao, F. S.; Curr. Opin. Colloid Interface Sci. 2005, 10, 94.

20. Karmakar, B.; De, G.; Ganguli, D.; J. Non-Cryst. Solids 2000 , $272,119$.

21. Moran, C. E.; Hale, G. D.; Halas, N. J.; Langmuir 2001, 17, 8376.

22. De, G.; Karmakar, B.; Ganguli, D.; J. Mater. Chem. 2000, 10, 2289.

23. Bekiari, V.; Lianos, P.; Chem. Mater., 1998, 10, 3777.

24. Ivanda, M.; Music, S.; Popovic, S.; Gotic, M.; J. Mol. Struct. 1999, 480-481, 645 .

25. Birnie, D. P.; J. Mater. Sci. 2000, 35, 367.

26. Pope, E. J. A.; Mackenzie, J. D.; J. Non-Cryst. Solids 1986, $87,185$.

27. Arenas, L. T.; Correa, C. P.; Gushikem, Y.; Dias, S. L. P.; Costa, T. M. H.; Benvenutti, E. V. Abstracts of the XXVI Congresso Latino Americano de Química and 27RASBQ, Salvador, Brasil, 2004.

28. Brunauer, S.; Emmett, P. H.; Teller, E.; J. Am. Chem. Soc. 1938, 60,309

29. Barret, E. B.; Joyner, L. G.; Halenda, P. P.; J. Am. Chem. Soc. 1951, 73, 373.

30. Guinier, A.; Fournet, G.; Small-Angle Scattering of X-Ray, Wiley: New York, 1955.

31. Glatter, O.; Kratky, O.; Small Angle X-ray Scattering, Academic Press: London, 1982

32. Xi, Y.; Liangying, Z.; Sasa, W.; Sens. Actuators B 1995, 24-25, 347.

33. Gregg, S. J.; Sing, K. S. W.; Adsorption, Surface Area and Porosity, Academic Press: London, 1982.

34. Pavan, F. A.; Hoffmann, H. S.; Gushikem, Y.; Costa, T. M. H.; Benvenutti, E. V.; Mater. Lett. 2002, 55, 378.

Received: September 27, 2006

Web Release Date: July 20, 2007

FAPESP helped in meeting the publication costs of this article. 